\title{
"SÓ DE VER A GENTE APRENDE": UMA ETNOGRAFIA DOS SABERES E PRÁTICAS ALIMENTARES DE MULHERES QUE VENDEM COMIDA EM SANTARÉM/PA
}

\author{
Marla Elizabeth Almeida Reis ${ }^{1}$ \\ Raquel Wiggers ${ }^{2}$ \\ Solon Pessoa Godinho Neto ${ }^{3}$
}

\section{INTRODUÇÃO}

$\mathrm{O}$ ato de comer e de preparar alimentos é repleto de sentidos pessoais, sociais, econômicos e psicológicos ${ }^{2}$. De acordo com Montanari (2008:15), as comidas que compõem a base alimentar são "resultados e representações de processos culturais que preveem a domesticação, a transformação e a reinterpretação da natureza". Assim, a preparação do alimento envolve conhecimentos e técnicas específicas que são adquiridas ao longo da vida e muito falam sobre o modo de viver e pensar da população local.

O objetivo deste artigo é analisar as escolhas alimentares que envolvem a atividade econômica de venda de comida aqui chamada de "botar banca", desenvolvida por mulheres em bairros populares de Santarém/PA, tais como: a transmissão do conhecimento, os modos de preparar e armazenar a comida e as relações de sociabilidade em torno da banca.

O botar banca é uma atividade econômica de venda de comida que ocorre em cima de uma mesa de madeira posicionada em frente à casa das vendedoras. Dentre as comidas mais comuns estão: tacacá, vatapá, mungunzá, salada de frutas, sucos, salgados, bolos, pudins e pratos de comida com churrasco completo e espetinhos de carne. As bancas começam a ser vistas pela cidade ao entardecer, por volta das 15 horas,

\footnotetext{
${ }^{1}$ Universidade Federal do Amazonas, Brasil. Email: marla-reis@hotmail.com ORCID id: https://orcid.org/0000-0002-9785-2909

${ }^{2}$ Universidade Federal do Amazonas, Brasil. Email: raqwiggers@gmail.com ORCID id: https://orcid.org/0000-0001-9900-8595

${ }^{3}$ Universidade Federal do Amazonas, Brasil. Email: solongodinho@gmail.com ORCID id: https://orcid.org/0000-0001-7372-6476

${ }^{2}$ Ver Certeau et al (1996), Fischler (1990), Corbeau (1995), Poulain, (2003; 2004) e Flandrin e Montanari (2008).
} 
e algumas se mantêm abertas até próximo das 21 horas, a depender da quantidade de clientes.

De forma analítica, pode-se definir o "botar banca" como uma categoria local que se caracteriza por: 1) ser uma atividade econômica informal, desenvolvida por mulheres que vendem comida; 2) a venda de comida ocorre em cima de mesas de madeira, colocadas na calçada, próximo a residência das vendedoras; 3 ) há variedade de comidas, e não lhe é outorgado a especialização de um prato, como por exemplo ocorre com as tacacazeiras ou vendedoras de acarajé; 4) Em geral, além da venda da comida a mulher desenvolve outras atividades econômicas simultaneamente como: venda de produtos por catálogos, venda de rifas de sorteios, venda de animais de pequeno porte, crochê, tricô etc.

A pesquisa que deu origem a este artigo ocorreu entre os anos de 2012 e 2018 na cidade de Santarém, localizada no oeste do estado do Pará, região Norte do Brasil, onde, de acordo com o IBGE, em 2010 havia uma população de aproximadamente 294.774 habitantes.

Segundo Mariza Peirano, “a etnografia é a ideia mãe da antropologia, e não há antropologia sem pesquisa empírica”. Consoante a isso, este trabalho se caracteriza como uma pesquisa etnográfica, qualitativa e empírica, com construção do objeto e levantamento teórico-etnográfico pertinente ao tema, pois "etnografia não é método; toda etnografia é também teoria" (Peirano, 2014: 383).

As técnicas de coleta de dados envolveram: trabalho de campo, observação sistemática direta, fotografia, diário de campo, aplicação de questionários, realização de entrevistas dirigidas e conversas informais com 22 mulheres que "botam banca" em Santarém, nos bairros Livramento, Interventoria, Santana e São José operário, localizados na área da Grande Prainha. Apesar de delimitar geograficamente a coleta de dados, a atividade econômica de "botar banca" ocorre em todos os bairros da cidade.

Essa pesquisa se mostra relevante por se propor a analisar, a partir do "botar banca" - forma popular de venda de comida -, como hábitos alimentares que se constituem no silêncio das cozinhas ${ }^{3}$ falam sobre modos de vida, organização social e a identidade da população local.

\footnotetext{
${ }^{3}$ Certeau et al (1996).
} 


\section{SÓ DE VER A GENTE APRENDE: AS MULHERES QUE "BOTAM BANCA” E A TRANSMISSÃO DO CONHECIMENTO}

As mulheres entrevistadas aprenderam a cozinhar ainda na infầncia, por volta dos 10 anos de idade, enquanto ajudavam as suas mães nas tarefas domésticas. Quando indagadas acerca disso, algumas mulheres alegam saber cozinhar "desde sempre", pois foram criadas em meio a tais atividades e passaram a ajudar nas tarefas mais simples desde terna idade, não sabendo dizer quando ao certo. Isso pode ser observado nas falas a seguir:

Eu aprendi a cozinhar vendo a minha mãe, ela não precisava nem me falar o que era para fazer, só de ver a gente já vai aprendendo né? (Viviane - 05/10/2012). Eu aprendi desde sempre, porque desde menina eu ajudava a minha mãe e fui aprendendo a fazer a carne, o baião, tudo! (Rosa - 28/05/2013)

Em geral tratavam-se de receitas do cotidiano como arroz, feijão, baião e o preparo de carnes. Em momentos especiais como festividades - sejam casamentos, festas de escola ou festas religiosas - as mulheres ficavam encarregadas de fazer as comidas regionais ${ }^{4}$ como vatapá, tacacá, mungunzá, bolo podre, bolo de milho, dentre outras. E assim as moças adquiriam o conhecimento e prática necessárias para a produção de tais iguarias.

Diversos são os fatores que levaram as mulheres a migrar para a cidade de Santarém, os mais recorrentes são: a incorporação dos seus bairros pela área urbana, acesso a saúde, conclusão dos estudos ou acompanhar o cônjuge que buscava trabalho na cidade.

Além disso, a mecanização da agricultura e o aumento da soja, associados às dificuldades em se manter no campo, têm proporcionado a migração de famílias pobres para a cidade de Santarém. Mas vale ressaltar que existe também grande curiosidade, principalmente por parte das moças, em conhecer a cidade, pessoas, dinâmicas e modos de vida dos espaços citadinos.

Ao mudar para a cidade de Santarém, essas mulheres trabalham como cozinheiras, empregadas domésticas, lavadeiras, babás ou vendedoras em lojas no

\footnotetext{
${ }^{4}$ As mulheres que não são provenientes do estado do Pará aprenderam a fazer comidas regionais com vizinhas, amigas e parentes por casamento.
} 
centro da cidade. No que concerne às atividades ligadas à culinária, estas foram paulatinamente aperfeiçoadas na execução diária da atividade e com o auxílio da patroa, que lhes ensinava a forma adequada de preparar determinados alimentos, de servir corretamente a comida ou utilizar determinados eletrodomésticos. Isso pode ser observado na fala a seguir:

Eu aprendi a cozinhar pequena ainda, com a minha mãe, mas era comida simples, de todo dia. Ai quando comecei a trabalhar como doméstica, em cada casa que eu trabalhava eu aprendia um jeito diferente, uma receita nova, foi assim que eu fui aprendendo. (Teresa - 04/06/2012)

De acordo com as interlocutoras, algumas das fontes disponíveis para aprender novas receitas eram revistas de culinária ou até mesmo as embalagens de produtos que traziam sugestões de como diversificar a utilização de tais ingredientes. Segundo elas, nos rótulos de produtos como trigo, creme de leite e leite condensado sempre havia receitas que elas recortavam e colavam em seus cadernos. Havia também o costume de copiar receitas que eram transmitidas em programas de televisão ou rádio.

Ao se indagar acerca do destino dos seus cadernos de receitas, muitas mulheres afirmaram que passaram para as suas filhas, mas demostraram insatisfação por elas não utilizarem e não valorizarem as receitas de família, conforme visto na fala a seguir:

\footnotetext{
Hoje em dia elas pegam tudo do computar né? Eu falo e ela [a filha] nem liga, entra num ouvido e sai no outro. Ela sabe que depois pode ir lá e ver de novo. Eu não, eu tinha que prestar atenção no que me ensinavam senão onde que eu ia ver de novo? Agora ela se confia que eu tô aqui e que tem escrito em todo canto, quero só ver quando eu morrer... acabou-se a torta de piracuí que eles tanto gostam. (Berenice 08/03/2017)
}

A continuação desses trabalhos assalariados geralmente é interrompida pelo nascimento dos filhos, pois os empregadores tendem a não aceitar a presença das crianças em seus estabelecimentos. Como a maioria das mulheres entrevistadas ocuparam cargos empregatícias por vias informais, estas não se valem de direitos trabalhistas como licença maternidade e não conseguem ou optam por não colocar os seus filhos em creches ou aos cuidados de terceiros.

Assim, o "botar banca" surge como uma atividade viável para as interlocutoras. Uma vez que elas adquiriram na infância o conhecimento necessário à execução do ofício, que foi aperfeiçoado posteriormente, a atividade pode ser desenvolvida em sua 
própria casa, pois possibilita horários flexíveis e o início da atividade não requer grande investimento financeiro.

Atualmente as interlocutoras possuem entre 40 e 60 anos de idade, sendo que destas (13) treze possuem relação conjugal, (4) quatro são viúvas, (1) uma é divorciada e (2) duas são solteiras. Observou-se que apenas (2) duas mulheres não possuem filhos, enquanto as demais possuem em média (3) três filhos. Porém, elas começaram a "botar banca" quando os seus filhos eram crianças. Atualmente várias dessas mulheres já possuem netos que ficam com elas aprendendo o oficio e brincando em torno da banca enquanto as filhas(os) vão trabalhar ou estudar.

Além de "botar banca", é muito comum que as entrevistadas desenvolvam também outras atividades econômicas no mesmo espaço, como por exemplo vender produtos de catálogos; vender peças de crochê ou tricô; costurar ou remendar roupas; vender galinhas que elas criam no quintal da casa etc. Nesse sentido, a banca favorece a execução dessas outras atividades.

Como as mulheres desempenhavam diversas atividades econômicas ao mesmo tempo, elas não demonstraram a necessidade de nomear os seus ofícios. Ao indagar qual o nome do oficio que as interlocutoras estavam praticando surgiam respostas como "eu trabalho com isso, vendendo comida nessa banca" ou "meu trabalho é esse, botar essa banca para fora, vender comida e depois colocar a banca para dentro". Algumas interlocutoras utilizavam a categoria "botar banca" de modo informal, não como algo pensado para definir o seu trabalho.

Um fator que me chamou a atenção e que demonstra como essas mulheres não estão preocupadas em dar nome ao trabalho que desenvolvem foi que, apesar de quase todas as interlocutoras venderem tacacá dentre as outras comidas, nenhuma delas se considerava tacacazeira.

\section{3. “ESSA RECEITA NÃO TEM MISTÉRIO": MODOS DE PREPARO E ARMAZENAMENTO DAS COMIDAS DA BANCA}

As populações que habitavam o Brasil antes do contato com os europeus domesticaram diversas espécies de plantas que serviram, e ainda servem, como base 
alimentar. Além disso, durante o processo de colonização do Brasil houve intensos intercâmbios entre as populações locais, povos africanos e europeus. Tal processo histórico influenciou o sistema culinário brasileiro, de modo que a alimentação hoje possui elementos característicos desses grupos. De acordo com Miranda (2003: 70):

\begin{abstract}
"No Brasil, os índios com alimentação à base de farinha de mandioca, peixes, caças, mostram uma culinária ecológica. Na costa, África, impera o dendê juntamente com inhames, bananas, pimentas, feijões entre outras delícias, como quiabos e camarões. Como se o Brasil fosse um enorme caldeirão, convivem e misturam-se diferentes e saborosas contribuições gastronômicas”. (Miranda, 2003: 70)
\end{abstract}

Os europeus, por sua vez, introduziram especiarias adquiridas em lugares distantes do mundo, por meio das grandes navegações. Dessa forma, a Índia, a Indonésia, a China, dentre outros países, também influenciaram a culinária brasileira. Assim, pode-se pensar na formação da culinária local como sendo heterogênea e resultante de múltiplos contatos.

A região Norte do Brasil é conhecida internacionalmente por suas comidas típicas. As transformações históricas e culturais locais refletiram-se diretamente nos hábitos alimentares da população local e se refletem nos tecidos, nas músicas, danças, formas de comer e socializar. Dessa forma, falar de comida é falar de cultura.

Pode-se compreender muito acerca da identidade e processos locais através do estudo das comidas vendidas nas bancas em Santarém/PA. Vamos observar, por exemplo, como o tacacá, uma das comidas de banca, pode nos falar sobre a cultura local e a trajetória das interlocutoras.

\title{
3.1 TACACÁ
}

O Tacacá é um caldo feito com o molho de tucupi, goma de mandioca ${ }^{5}$, folhas de jambu $^{6}$ pré-cozido e camarões secos dessalgados e cozidos. O prato possui cor amarelada e é montado na hora, servido quente, geralmente apimentado e em cuias. Luciana Carvalho (2007:70) ao falar sobre a região de Santarém afirma que as cuias são "feitas do fruto de uma árvore conhecida como cuieira (Crescentia cujete), tingidas com

\footnotetext{
${ }^{5}$ Substância transparente extraída da mandioca.

${ }^{6} \mathrm{O}$ jambu é uma planta ramosa, rasteira, picante e com flores amareladas. (Dorneles, D.; Chaves, C., 2002: 279)
} 
pigmentos naturais e decoradas com motivos gráficos, são bastante tradicionais na região". Utilizam-se palitos para pegar o jambu e os camarões.

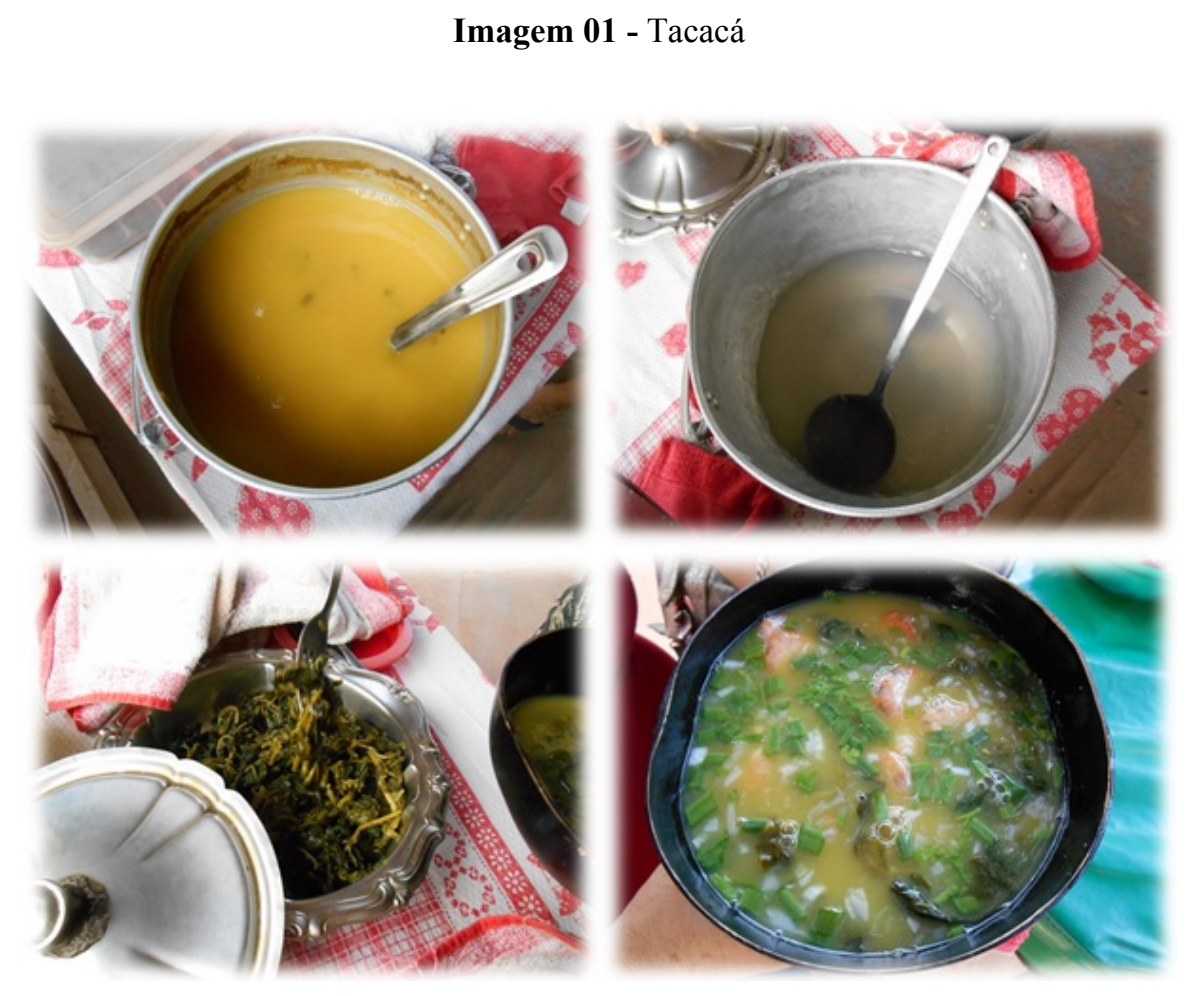

Na primeira imagem acima pode-se ver o tucupi, na segunda a goma, na terceira as folhas de jambu cozidas e por fim o Tacacá pronto servido na cuia.

Fonte: Autora.

O dossiê do tacacá, realizado pelo IPHAN (2018:7), afirma que essa iguaria é "a um só tempo líquido e sólido, que não é comido nem bebido, mas tomado numa cuia que, por sua vez, não é prato nem tigela". Segundo o mesmo autor, o tacacá é um prato antigo, consumido em diversas regiões da Amazônia brasileira pelas populações locais desde o século 18, sendo citado por viajantes como o Padre João Daniel (1741-1757) e Alexandre Rodrigues Ferreira (1756-1815).

Esse alimento, assim como outras comidas regionais, ganha força em festejos religiosos e datas comemorativas. Em Santarém, é comum ouvir a expressão "a hora do tacacá", que segundo as interlocutoras é ao entardecer por volta das 16 horas até as 20 horas. Esses horários não são rígidos, mas representam os períodos de maior movimento nas bancas atrás dessa iguaria. 
O tacacá da região de Santarém se diferencia do de outras cidades amazônicas como Manaus e Belém por possuir um tucupi adocicado, enquanto os demais tucupis contêm sabor azedo. Além disso, pode-se acrescentar ao tacacá pronto cebolas cortadas e cheiro verde. As receitas são passadas de mãe para filha por transmissão oral. Segundo Mariana, para fazer o tacacá "não tem mistério":

\begin{abstract}
"O meu tacacá é assim, coloco a água no fogo com uma pitada de sal, depois quando pegar fervura, eu misturo a tapioca nessa água. Aí fico mexendo até virar uma goma, quando vira eu apago o fogo. Depois de fazer a goma eu vou temperar tucupi. Corto o alho, cebola, cheiro verde e pimenta de cheiro e coloco junto com o tucupi numa panela. O segredo para fazer um bom tucupi é ferver bem, porque aí pega bem o gosto dos temperos". (Mariana - 10/05/2017)
\end{abstract}

Na receita de Mariana, destaca-se a necessidade de "ferver bem" o tucupi para que o tacacá fique gostoso e pegue o sabor dos temperos. O tucupi é um suco amarelado e azedo extraído da mandioca após ser descascada, ralada, espremida e guardada de três a cinco dias. O tucupi é venenoso após ser retirado da mandioca brava devido à forte presença de ácido cianídrico, que é eliminado através do processo de cozimento e fermentação por cerca de 4 dias. Sempre é aconselhado a quem trabalha com tucupi fervê-lo bem, seja para garantir a absorção dos temperos ou para a eliminação do veneno.

O constante processo de fervura do tucupi corrói panelas de alumínio em que são preparados. Por isso, sabe-se que uma mulher vende tacacá há muito tempo quando as suas panelas de tucupi têm vários "remendos" feitos com durepoxi". Além do tacacá, são muito comuns nas cidades da Amazônia comidas como o arroz paraense, pato no tucupi e peixes no tucupi.

As mulheres entrevistadas compram o tucupi após o processo de fervura do caldo e em casa o fervem novamente e acrescentam os temperos. A presença de cuias em cima das bancas sinaliza a venda dessa iguaria. Nas bancas onde foi realizada a pesquisa era comum o uso de cuias de tamanho médio e sem decorações. A cuia esquenta bastante quando é enchida com o caldo quente, por isso ela é acompanhada por um suporte artesanal de cestaria que serve para dar sustentação para que a cuia não entorne.

\footnotetext{
${ }^{7}$ Massa que funciona como adesivo bastante resistente.
} 
Embora esse alimento também seja feito no espaço familiar, é perceptível a sua presença nas ruas das cidades amazônicas, seja em pontos turísticos ou bairros periféricos, em rodas de conversa ou em rodas de carimbó, em ambientes públicos e privados. O tacacá também é consumido por pessoas de diversas classes econômicas, podendo custar de 5 a 25 reais, de acordo com o local da venda.

\title{
3.2 VATAPÁ
}

O vatapá é um prato apimentado, de textura cremosa e amarelada feito com trigo, azeite de dendê e leite de coco, podendo conter camarão ou frango. O vatapá é temperado com sal, cebola, pimentão, tomate, coentro e cheiro-verde, ele é servido junto com o arroz em um prato descartável. Juliana, de 42 anos, ensinou a sua receita. Segundo ela:

\begin{abstract}
Você pega o camarão seco e descasca, depois coloca de molho na água gelada para tirar bem o sal. Aí coloca o camarão para refogar na panela com o azeite de dendê, cebola, alho, cheiro-verde, pimentinha de cheiro, tudo bem cortadinho. Ai na outra panela você coloca o leite de coco, um creme de leite, um pouco de água e vai colocando o trigo aos poucos. Aí vai batendo bem pra não dar bolinha de trigo, ele tem que ficar parecendo um mingau bem mole. Aí você joga esse mingau na panela com os temperos e o camarão, e vai mexendo. Quando tu deres fé o trigo vai começar a engrossar e vai ficar bem amarelinho por causa do dendê. Tem que cozinhar bem o trigo, pegar o gosto do camarão e dos temperos, aí ta pronto. Mas olhe, vatapá bom é vatapá de um dia pro outro! (23/06/2014)
\end{abstract}

O vatapá geralmente é servido apenas com arroz, mas algumas mulheres, para incrementar a aparência do prato, colocam entre o arroz e o vatapá uma fileira de folhas de jambu e três camarões. Segundo Mascarin (2015:63), o vatapá é de origem africana. A sua forma de preparo e a essência de alguns ingredientes característicos foram mantidos. No entanto, juntamente com esses foram acrescentados outros ingredientes locais.

Na Nigéria não há prato especificamente idêntico ao vatapá. O leite de coco não
possui lá a presença que usufrui no Brasil. [...]. O mistério da origem do vatapá não
exclui a pátria africana ocidental, banto ou sudanesa. [...]. Lógico é sugerir que o
pitéu teve desenvolvimento e características na Bahia, vindo em forma mais simples
da pátria negra. [...]. O vatapá continua evoluindo, complicando-se na elaboração
culinária pela adiçãa e substituição dos componentes. (Mascarin, 2015:63 apud
Cascudo, 2004:833)

De acordo com Delzanita Carvalho, de 43 anos, “o vatapá de verdade é feito com camarão, mas o camarão é reimoso e tem muita gente que não pode comer, fora 
que ele é bem caro também, por causa disso começaram a fazer o vatapá de frango". Segundo Delzanita, a receita tradicional do vatapá, consumida em lugares mais elitizados e pontos turísticos, é feita com camarão, porém, por conta do alto preço deste ingrediente, ele foi substituído por frango, que é mais barato e "enche mais", ou seja, é um recurso economicamente viável para famílias mais pobres. "É muito difícil ver vatapá de frango em ponto turístico ou em lugar de gente chique. O vatapá de frango é mais de pessoas pobres. Sempre tem em aniversário, casamento... tudo quanto é festa! Porque ele é barato, todo mundo gosta e enche bastante" (Delzanita - 23/06/2014).

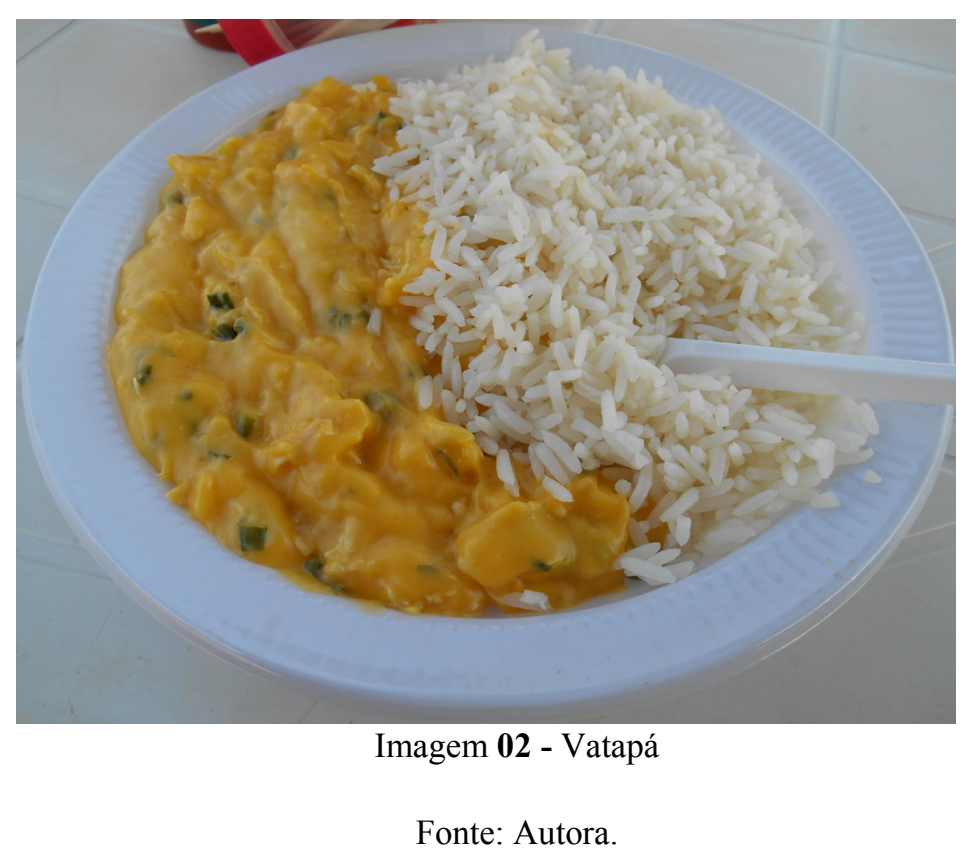

\subsection{MUNGUNZÁ}

O Mungunzá, do quimbundo mu'kunza, que significa "milho cozido", tem origem africana. É um mingau feito com milho branco cozido, doce, servido frio em copos descartáveis. É comum acrescentar canela em pó em cima do mungunzá. Também é conhecido como "canjica" em alguns estados brasileiros. No relato abaixo, pode-se observar o preparo de tal alimento:

"O milho do mingunzá é duro. É aquele milho branco. Aí eu gosto de deixar ele de molho de um dia para o outro, para amolecer. No outro dia, quando eu for colocar ele na panela de pressão, ele vai ficar pronto mais rápido [...]. Depois de cozinhar o milho na panela de pressão eu coloco o leite. O leite é o mais importante pro mungunzá ficar gostoso e bem cremoso. Não pode ficar ralo, mas também não pode ficar muito caro pra fazer, se eu colocar muito creme de leite e leite condensado, vai ficar mais caro. Aí eu pego um pouco o milho e bato com leite de gado no liquidificador, porque assim eu uso o próprio milho pra deixar o mingau mais grosso e cremoso. Depois de bater o leite e um pouco de milho eu coloco o creme de leite, 
leite de coco e leite condensado, e depois eu misturo isso ao resto do milho". (Entrevistada 11 - 04/05/2017)

Apesar de ser vendido durante o ano inteiro, o consumo do mungunzá se intensifica nas festas religiosas das cidades da Amazônia, em especial nas festas juninas, onde várias bancas são colocadas na praça da igreja e visam arrecadar dinheiro para diversos fins como a reforma da paróquia. Segundo Rita, 66 anos, ajudar nas festas dos santos faz com que eles abençoem a atividade econômica dela. Além disso, muita gente que não conhecia a comida dela acaba comendo nas festas da igreja e gostando, e depois acabam se tornando fregueses da sua banca.

Imagem 03 - Mungunzá

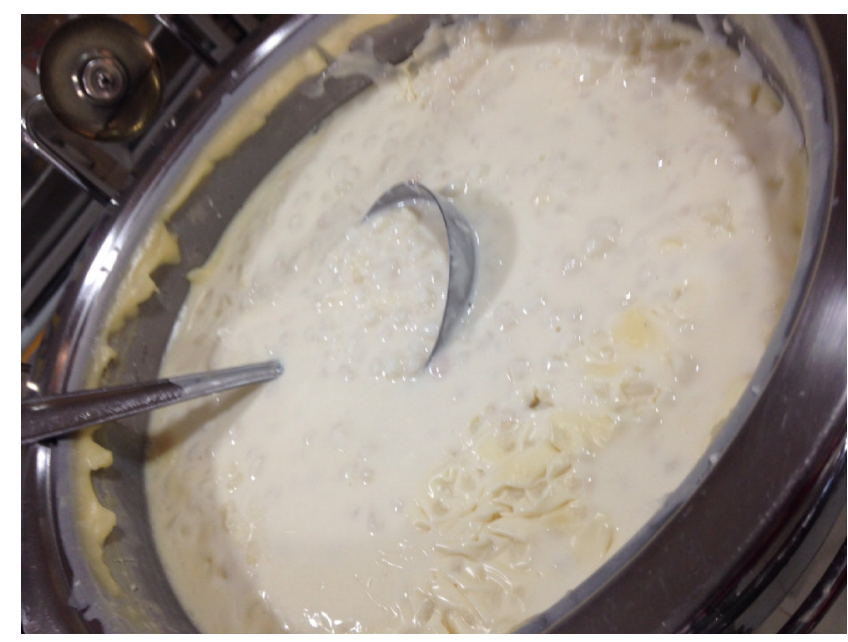

Fonte: Autora.

\subsection{CHURRASCO}

O churrasco é vendido em bancas que funcionam no período da noite. O churrasco pode ser de frango, carne, linguiça ou misto, isto é, com dois ou mais tipos de carne. Ele pode ser vendido de duas formas: completo - acompanhado com baião, farofa e salada; ou simples, onde a carne é servida em um espeto, acompanhada de um copo pequeno de farofa, também conhecido como churrasquinho. 


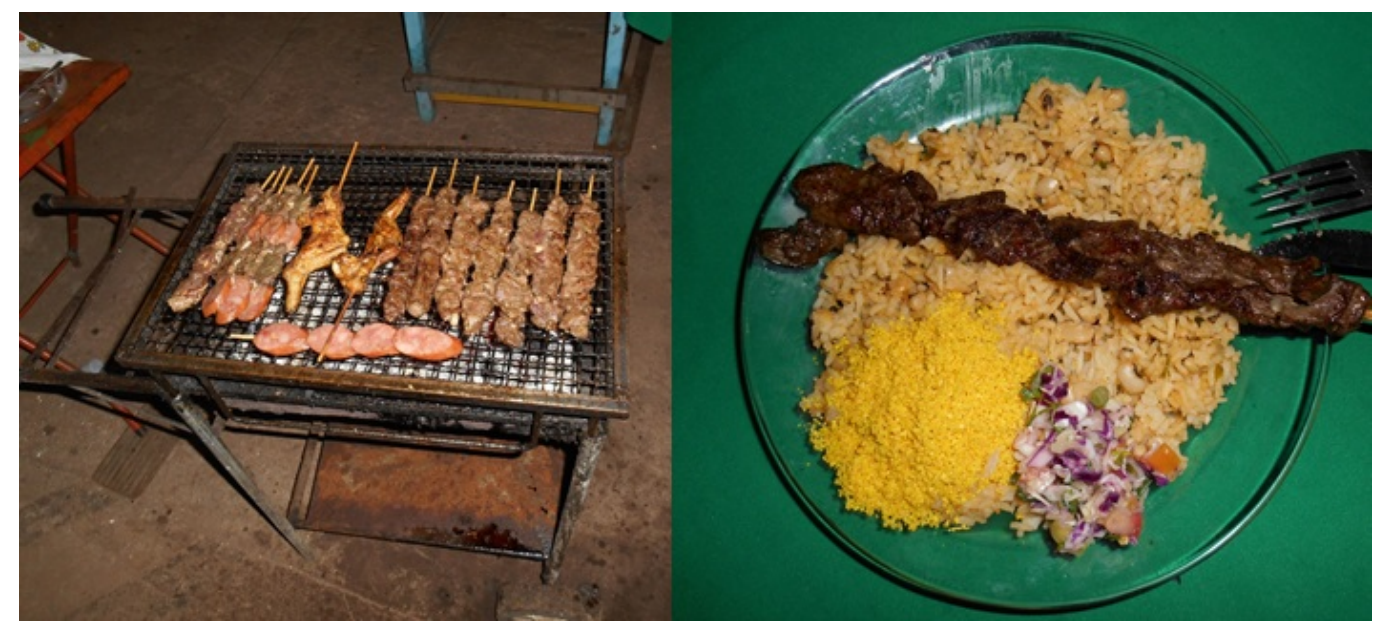

Imagem 04: Churrasquinho

Pode-se ver no primeiro quadro os churrasquinhos sendo preparados na churrasqueira a brasa, e no segundo quadro o churrasco completo, servido com baião, farofa e salada. Fonte: Autora.

A compra da carne e a preparação desta geralmente ficam ao encargo do homem da família. O processo de fazer o churrasco envolve levar a churrasqueira para fora, colocar o carvão e fazer o fogo. Existem técnicas diferentes de "fazer o fogo". Segundo João Celestino, 47 anos:

\footnotetext{
"Para fazer o fogo tem que colocar um papel molhado com óleo no meio do carvão. Aí acende o papel, ele vai começar a pegar fogo aos poucos, demora um pouquinho. Aí eu fíco com um papelão abanando, para o fogo crescer e pegar no carvão". (João Celestino - 19/06/2015)
}

Alguns dos homens com os quais conversei utilizavam outras técnicas, como por exemplo embeber o algodão em álcool e colocá-lo no centro de um "montinho" de carvão, ou até mesmo utilizar madeira em vez de carvão. João Celestino ainda contou que "o fogo não pode ser feito de qualquer forma, pois isso poderia deixar a carne ruim". Para ele, "o fogo tem que ser acendido antes, que é pra dar tempo de queimar o carvão. Se alguém fizer o fogo e logo depois colocar a carne, vai estragar a carne, com certeza! Porque vai ficar só o fedor da fumaça preta”. Além disso, é necessário calcular a distância que a carne ficará do fogo, pois "se ficar perto demais vai queimar por fora e ficar crua por dentro", e se a carne ficar muito longe do fogo, "vai demorar muito tempo para ficar pronto".

Existem casos em que a mulher faz o churrasco, mas em geral, mesmo nesses casos, o homem da família compra a carne e prepara o fogo, embora não 
necessariamente asse a carne. Mesmo nas bancas onde os homens fazem o churrasco, geralmente o nome da banca é atribuído à figura feminina, como por exemplo a "banca da dona Rosa", que é reconhecida assim pelos fregueses apesar de ela receber "ajuda" do seu marido e filho.

As bancas que vendem churrasco se diferenciam das demais bancas por serem maiores, em geral tratam-se de mesas de madeira largas o suficiente para caber as panelas de arroz ou baião, vinagrete, farofa, salada, os pratos, talheres, copos descartáveis, marmitas de plástico, dentre outros materiais. Ao redor dessas bancas há cerca de 3 ou 4 mesas, onde sentam-se os clientes. Em alguns casos pessoas compram a comida e pedem "para levar". Nesse caso a comida é colocada em marmitas descartáveis e entregue aos clientes.

Nas bancas que vendem churrasco também podem ser vistos outros alimentos como bolos, pudins, saladas de fruta e sucos. Em pesquisa anterior percebi que "a banca é organizada de modo a delimitar o que pode ser tocado pelos clientes e o que só pode ser tocado pela vendedora" (Reis, 2016: 31).

Assim, as cuias, pimenta, palitos, saleiro, farinheira, molhos (ketchup, mostarda, azeite/óleo composto, vinagre), guardanapos, pratos e talheres ficam mais próximos dos fregueses, na banca ou em mesas de plástico onde o cliente pode sentar e comer. Já as panelas com o complemento do churrasco, vatapá, tacacá etc. ficam próximas à vendedora, e apenas a responsável pela banca e, em alguns casos, os encarregados em ajudá-la podem manipular os alimentos. Essa é uma forma das mulheres manterem o controle sobre a higiene do alimento e também para uniformizar a quantidade servida nos pratos.

\subsection{SALGADOS E BOLOS}

Dentre as comidas vendidas nas bancas, é comum encontrarmos salgados como: croquetes, que são feitos com massa de mandioca cozida, amassada e temperada, recheados com carne moída e depois fritos; as empadas, que são assadas, feitas com farinha de trigo, ovos, manteiga, gordura vegetal, temperado com sal e recheadas com creme de frango desfiado ou carne desfiada; os rissoles, que possuem formato de pastel e são feitos de farinha de trigo cozida com caldo de galinha e leite, recheados com carne moída ou frango desfiado; e as coxinhas, que são feitas com trigo, leite, caldo de galinha e margarina, podendo ser recheadas com frango desfiado ou carne moída. 
Nesse caso é comum haver uma estufa em cima da banca para armazenar os salgados, ou quando não há condição financeira para comprar a estufa, as mulheres colocam papel alumínio dentro de um isopor de tamanho médio e colocam os salgados dentro para serem mantidos quentes.

A preparação dos salgados ocorre uma ou duas vezes por semana, dependendo da demanda. Depois disso eles são congelados ainda crus. Dessa forma a cada dia descongelam uma porção e fritam ou assam para serem servidos naquele dia. Segundo REIS (2016: 30) "se por acaso o salgado acabar cedo - no meio da tarde quando ainda falta bastante tempo para encerrar a venda -, elas podem descongelar e preparar rapidamente mais alguns salgados".

Os bolos vendidos na banca são simples, geralmente de chocolate, milho ou macaxeira. Apesar de não serem confeitados, alguns são recheados com chocolate e possuem cobertura, geralmente de chocolate, cupuaçu ou coco. Em geral prepara-se apenas um sabor de bolo por dia e vende-se a fatia.

Já os pudins são de leite, chocolate ou maracujá. Os bolos, assim como os pudins, são armazenados em recipientes de plástico transparentes. Dessa forma os clientes podem ver o produto sem que seja preciso abrir o recipiente. Ambos são servidos em pratos descartáveis.

\subsection{SUCOS E SALADAS DE FRUTA}

Os sucos mais comuns são de frutas regionais como acerola, maracujá, cupuaçu, taperebá (também conhecido como cajá nas regiões Sul e Centro-Oeste brasileiras) e murici. Para a fabricação dos sucos, as mulheres armazenam a polpa das frutas no congelador, em pequenos sacos plásticos ou potes. Essa forma de dividir as polpas em porções facilita na hora de descongelar a quantidade diária que será utilizada para a fabricação dos sucos. Geralmente nas bancas são ofertados apenas dois tipos de suco por dia. Os sucos são doces, gelados, guardados em garrafas de plástico e servidos em copos de $500 \mathrm{ml}$.

A salada de frutas é feita com frutas cortadas em pequenos pedaços, sendo estas: abacate, abacaxi, maçã, banana e mamão. Depois acrescenta-se suco de laranja e leite condensado. A salada de frutas é vendida gelada e nas bancas é difícil encontrar frutas importadas que são mais caras como morango, pêra, pêssego e uva. 
Imagem 05 - Locais de conservação dos alimentos frios
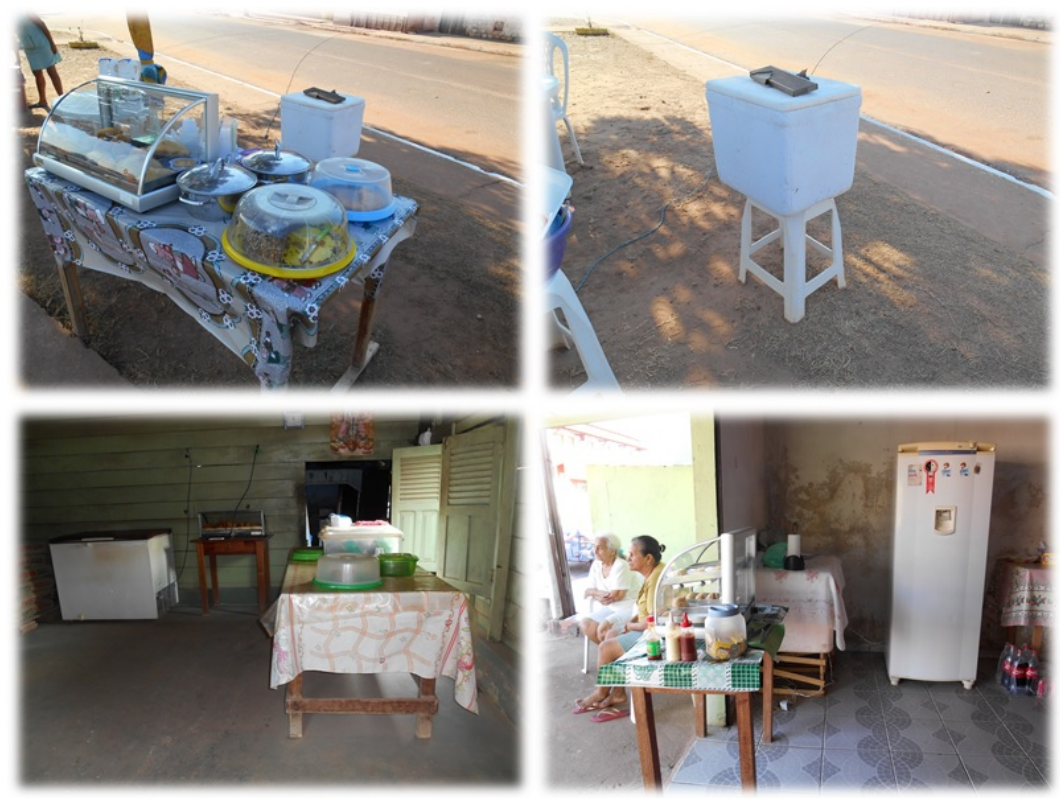

$\mathrm{Na}$ imagem acima pode-se observar um isopor próximo à banca, um freezer e uma geladeira. Fonte: Autora.

Os sucos e saladas de frutas são vendidos em copos de plástico descartável. Em pesquisa anterior percebi que "o local onde os sucos, saladas de frutas e demais alimentos vendidos frios são armazenados depende da condição financeira da vendedora e também da posição da banca” (Reis, 2016:34).

Assim, quem "bota banca" na praça em frente à sua casa, por exemplo, não pode levar a geladeira, por isso se utiliza de um isopor. Já a mulher que "bota banca" na área de casa pode utilizar a geladeira da sua cozinha, ou até mesmo um freezer. Conforme pode ser visto na imagem a seguir:

\section{4. "COMER E OLHAR A RUA": A SOCIALIZAÇÃO EM TORNO DAS BANCAS}

Ao redor da banca são formadas "rodas de conversa" onde sentam-se a vendedora, alguns familiares, vizinhos, amigos e passantes. Em casos onde esgotam-se as cadeiras da vendedora é comum que os vizinhos levem cadeiras para a rua afim de sentarem e conversarem em torno da banca enquanto "olham a rua".

As pessoas que participam das rodas de conversa abordam os temas mais 
diversos. Conversam sobre o passado, os antigos amigos, parentes, como as coisas eram e como são agora. Nesse ato de rememorar, muitas informações e valores são transmitidos aos mais jovens, que embora não tenham vivido determinadas situações, crescem ouvindo sobre elas.

Outros assuntos são política, religião, estudo, casamentos ou divórcios, os preços das coisas, festas e eventos que acontecem no bairro ou na cidade. Essa diversidade de assuntos se dá, também, pela presença de várias faixas etárias, de modo que os homens conversam entre si, mas também conversam com as mulheres, jovens, crianças e idosos.

É comum falarem de si mesmas, das suas famílias, da vizinhança. Assim essas pessoas se atualizam sobre os acontecimentos do bairro, das pessoas que frequentam a roda de conversa e sobre demais moradores que não a frequentam.

Imagem 06 - As rodas de Conversa

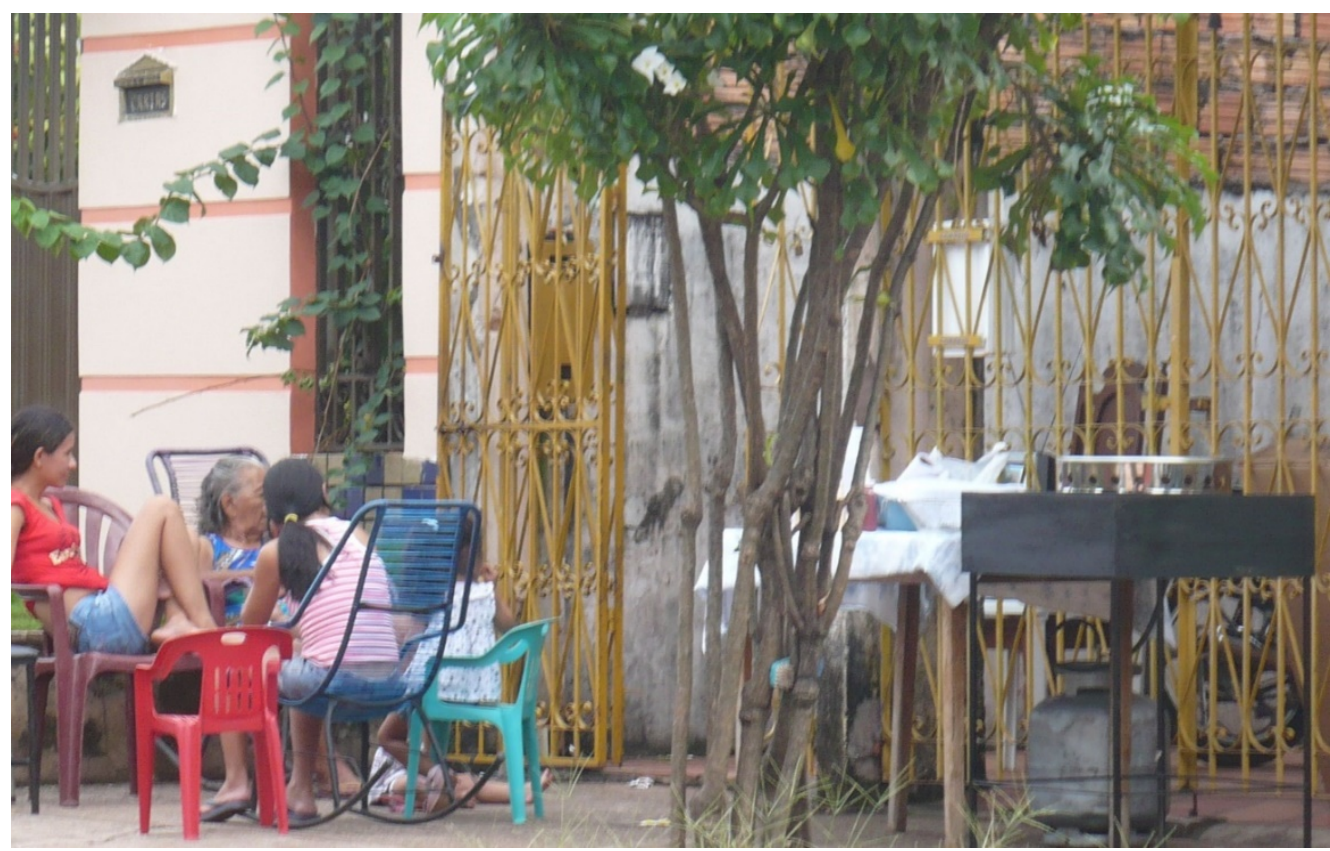

Fonte: Delma Pessanha Neves, 2013.

A fofoca está presente nas rodas de conversa. Embora ninguém se declare "fofoqueiro", todos alegam que ela exista. Segundo Fonseca (2000:44), o medo de "cair na boca povo" rege muitos comportamentos e escolhas individuais em bairros onde os vizinhos exercem esse poder de controle de comportamento através de redes de relações onde a fofoca serve para informar sobre a reputação dos moradores de um local, consolidando ou prejudicando a sua imagem pública. Segundo a autora:

A fofoca seria instrumental da definição dos limites do grupo - não se faz fofoca sobre estranhos, pois a estes não se impõem as mesmas normas; ser objeto, sujeito 
da fofoca, representa a interação no grupo. A fofoca pode ter uma função educativa. Em vez de adultos explicarem as normas morais a seus filhos, estes, ao ouvir as histórias de comadres, aprenderiam as nuances práticas dos princípios. (Fonseca, 2000: 42)

Essas rodas de conversa também funcionam como mecanismos de controle social, pois lá circulam as notícias sobre o que tem acontecido na cidade e no bairro, e são emitidas impressões sobre o comportamento dos moradores. Essas impressões são carregadas de aprovação ou reprovação segundo os códigos de conduta socialmente estabelecidos.

Em assentamentos urbanos de pequeno porte, mais simples do que metrópoles, o controle sobre o comportamento aceitável em público, quando não sobre a criminalidade, parece funcionar com mais ou menos êxito por meio de um emaranhado de condutas, comentários, aprovação, desaprovação e sanções. (Jacobs, 2009: 75)

As rodas de conversa podem simbolizar também o status da responsável pela banca. Portanto, se a mulher que coloca a banca consegue reunir diversos familiares e vizinhos em torno da banca, significa que ela tem certo prestigio dentro desse grupo. Nesse caso ter prestigio não é só cozinhar bem, mas corresponder aos ideais de conduta considerados adequados pelo grupo, de modo que não é qualquer mulher que pode colocar banca e ser "bem-sucedida".

Sem essa "aprovação" dos moradores do bairro é difícil a banca se manter, uma vez que a sua existência é sustentada por passantes, mas na maioria do tempo pelos moradores do bairro que preferem frequentar a banca do que ter que se locomover até o centro da cidade em busca de alternativas de lazer.

Em Santarém existe uma valorização da mulher enquanto mãe, dona de casa e esposa, e principalmente enquanto mulher "trabalhadeira", que não é preguiçosa e consegue desenvolver bem atividades domésticas, familiares, além do trabalho. Enquanto que a preguiça, a fofoca e o adultério são características condenáveis. Observar quem pode e quem não pode colocar nos fala muito sobre as regras de conduta socialmente estabelecidas dentro dos bairros analisados.

O momento do trabalho também é uma alternativa de lazer para essas mulheres. Ao final da tarde, quando colocam as suas bancas de comidas, sentam-se em bancos ou cadeiras na rua e ficam "olhando o movimento" e conversam com parentes e com outras 
mulheres da vizinhança. Nesse momento podemos verificar a importância dos laços de proximidade entre as vendedoras e os frequentadores da banca.

Segundo Dumazedier (1976), o lazer surgiu na Europa por volta do século XIX, esta era compreendida como dependente do trabalho, mais especificamente do trabalho industrial capitalista. Assim, o lazer era considerado "como uma liberação periódica do tempo de trabalho". Já Gomes (2014) considera desnecessária a dicotomização entre o trabalho e o lazer, característica típica das sociedades ocidentais industriais que não contempla outras formas de utilização dos tempos e outras noções de trabalho.

Mais do que um ambiente de lazer para as vendedoras, o local da venda de alimentos serve como alternativa de lazer para a vizinhança, devido à distância do bairro até o centro ou a orla da cidade, que são os principais locais de lazer em Santarém. A família sai junta para lanchar em uma banca de alimento dentro do bairro e com quem os membros da família possuem uma relação de camaradagem.

A clientela é constituída por vizinhos e amigos, com os quais essas mulheres mantêm relações de confiança. Por isso elas afirmam não se importar com a concorrência, acreditando que os restaurantes, lanchonetes e outras pessoas que botam banca não interferem na economia desenvolvida por elas, porque se valem de uma oferta por proximidade, eliminando gastos com passagens e planejamento para se dirigirem ao mercado do centro da cidade. "Outrossim, orientam-se exatamente por demandas que se conformam com a vida local e o atendimento de necessidades imediatas" (Reis, 2016).

\section{CONSIDERAÇÕES FINAIS}

A estreita relação entre comidas e manifestações culturais locais pode ser evidenciada pela letra de carimbó a seguir: "Oi mexe, mexe, menina. Pode mexer sem parar. Você agora é a minha garota do tacacá. Rala, rala a mandioca, espreme no tipiti, separa na tapioca e apara o tucupi. Prepara meu tacacá, gostoso com açaí" (Pinduca, 2016).

A música e a dança falam sobre o processo de obtenção do tucupi e preparo do tacacá. Além disso, as cores e padrões de estampas presentes nas roupas dos dançarinos 
nas rodas de carimbó se assemelham aos tecidos das bancas e falam bastante sobre a cultura popular. Segundo Da Costa (2011:3), essa forma de música "estava viva à maneira do toque indígena no instrumento, que tem ressonâncias africanas, o que o levava a concluir o caráter mestiço da manifestação”. A chita estampada não está presente apenas nas roupas dos dançarinos das rodas de carimbó, mas também nas mesas onde são colocadas as iguarias regionais, como o tacacá e o vatapá.

Diversos processos históricos fizeram com que famílias do interior do estado do Pará migrassem para as cidades mais populosas como Belém ou Santarém buscando empregos e/ou estudo para os seus filhos, como ocorreu com as mulheres que "botam banca", por exemplo. Até os dias de hoje é comum os pais mandarem suas filhas para a cidade para trabalharem como empregadas domésticas ou babás em casas de família, visando a conclusão do ensino escolar.

Esses processos de migração de camponeses para as cidades trouxeram consigo também elementos culturais mais interioranos, que são expressos e disseminados principalmente pelas mulheres, como por exemplo a música, a vestimenta e a alimentação. Oliveira e Vela (2008: 2), ao analisarem o cotidiano alimentar de famílias rurais do município de Jaboticaba, região do Médio-Alto Uruguai, Rio Grande do Sul, observaram que:

A mulher se comporta como figura central no processo de produção e reprodução, a ela competem as tarefas de alimentação, desde o cultivo, preparo e servida da comida à mesa. É responsável pelo cuidado com os animais - limpeza, alimentação, ordenha -, trabalho na horta, além de todas as etapas no preparo da comida de consumo doméstico, processamento dos alimentos e produtos próprios para a venda e consumo interno, como queijo, nata, chimia, doce em calda, rapadura, pão, bolo, cuca. A decisão também permeia quais alimentos e o modo como serão cultivados na horta, bem como o uso, ou não, de outros alimentos oriundos da lavoura ou do mercado determinando o cardápio doméstico. Assim, pois, constata-se a centralidade da mulher no processo decisório alimentar, daqueles alimentos que serão interiorizados no ambiente doméstico e daqueles que serão destinados à venda. (Oliveira; Vela, 2008: 2)

Quando tais famílias migram para as cidades, a mulher ainda é a responsável por decidir o que será consumido pela família. E nos casos das mulheres que "botam banca" existe uma ampliação das escolhas alimentares que se estende à clientela.

A pesquisa revelou que dentre as 22 mulheres entrevistadas, (8) oito são provenientes dos arredores de Santarém, isto é, de bairros que antes eram considerados áreas rurais e aos poucos foram incorporados pela cidade; (10) dez migraram de cidades do interior do estado para Santarém; e (4) quatro são de outros estados, sendo estes o 
Ceará e o Rio Grande do Sul. Dessa forma percebe-se que grande parte das interlocutoras são provenientes de áreas rurais e, embora morem na cidade de Santarém, ainda mantêm em suas relações diversas características camponesas.

As interlocutoras aprenderam a cozinhar ainda na infância quando auxiliavam as suas mães nas atividades domésticas. Ao migrar para a cidade, essas mulheres ocuparam trabalhos assalariados como vendedoras, empregadas domésticas, cozinheiras, babás e lavadeiras. Com a maternidade optaram ou foram obrigadas a sair de seus empregos. Nesse contexto, o "botar banca" surgiu como uma atividade econômica viável que lhes permitia cuidar dos filhos pequenos e garantir os recursos essenciais para a sobrevivência do grupo familiar.

Os hábitos alimentares que se expressam na forma das comidas vendidas na banca, as receitas, modos de transmissão do conhecimento, forma de armazenagem e as relações sociais que ocorrem em torno das bancas falam sobre as trajetórias, lógicas e a identidades desses sujeitos e visam corroborar com os estudos acerca da temática.

\section{REFERÊNCIAS}

CARVALHO, Luciana. Cuias de Santarém: tradição, mercado e mudança em comunidades artesanais da Amazônia. Textos Escolhidos de Cultura e Arte Populares, Rio de Janeiro, v. 4, n. 1, p. 69-78, 2007.

CASCUDO, Luís da Câmara. Contos tradicionais do Brasil. São Paulo: Global, 2004.

CERTEAU, Michel de; GIARD, Luce; MAYOL, Pierre. A invenção do cotidiano 2: Morar, cozinhar. Petrópolis: Vozes, 1996.

CORBEAU, Jean-Pierre. L'imaginaire associée à divers types de consommation de gras et les perceptions de leur qualités. In: NICOLAS, François; VALCESCHINI, Egizio (Org.). Agro-alimentaire: une économie de la qualité. Paris, INRAEconomica, p. 93-107, 1995.

DA COSTA, Tony Leão. Carimbó e Brega: Indústria Cultural e Tradição na música popular do norte do Brasil. Revista de Estudos Amazônicos, Belém, 2011.

DE OLIVEIRA, Nádia R. F; VELA, Hugo Aníbal. Escolhas alimentares, decisões culturais: a mulher define o que vai pra mesa. In: SEMINÁRIO INTERNACIONAL FAZENDO GÊNERO, 8., 2008, Florianópolis.

DORNELES, Darlan M; CHAVES, Lindinalva. Breve glossário do tacacá. Revista Philologus, Rio de Janeiro, Ano 20, n. 58, 2014

FISCHLER, Claude. L'homnivore. Paris: Éditions Odile Jacob, 1993. 
FLANDRIN, Jean-Louis; MONTANARI, Massimo. História da Alimentação: dos primórdios à Idade Média. Tradução de Maria da Graça Pinhão. Lisboa: Terramar, 2008.

FONSECA, Claudia. Família, Fofoca e Honra: etnografia de relações de gênero e violência em grupos populares. Porto Alegre: Editora da Universidade Federal do Rio Grande do Sul, 2000.

IBGE. Censo demográfico 2010. Brasília, 2010.

JACOBS, Jane. Morte e vida nas grandes cidades. São Paulo: Martins Fontes, 2009.

MELLÃO, Renata; IMBROISI, Renato. Que Chita Bacana. São Paulo: A Casa, 2005.

MONTANARI, Massimo. Comida como cultura. São Paulo: Editora Senac, 2008.

NEVES, Delma P. Lavradores e Pequenos Produtores de Cana. Rio de Janeiro: Zahar 1981.

NEVES, Delma P. Mulheres e mercado de trabalho: Aflições e conquistas. Mulheres em Santarém: Alternativa de vida (vol. I). Niterói: Editora alternativa, 2014.

PEIRANO, Mariza. Etnografia não é método. Horizontes Antropológicos, Porto Alegre, Ano 20, ed. 42, p. 377-391, 2014

PINDUCA E BANDA. Menina, menina. In: . Carimbó e sirimbó do Pinduca. Beverly Som e Eletrônica LTDA (AMCLP - 5194), p1973. 1 LP. Faixa A2.

PINDUCA E BANDA. Faixa Sinhá Pureza. In Carimbó e sirimbó no embalo do Pinduca (v.2). Beverly Som e Eletrônica LTDA (AMCLP - 5194), 1974. 1 LP. Faixa B1.

POULAIN, Jean-Pierre. Sociologia da alimentação: os comedores e o espaço social alimentar. Tradução de Rossana Pacheco da Costa Proença, Carmen Sílvia Rial e Jaimir Conte. Florianópolis: UFSC, 2004.

POULAIN, Jean-Pierre; PROENÇA, Rossana Pacheco da Costa. O espaço social alimentar: um instrumento para o estudo dos modelos alimentares. Revista de Nutrição, Campnas, v.16, n.3, p.245-256, 2003.

REIS, Marla. Mulheres e a venda de comida em bairros periféricos de Santarém/PA. Santarém: Ufopa, 2016.

ROCHA, Maria Diaz; QUEIROZ, Mônica. O significado da cor na estampa do tecido popular: a chita como estudo de caso. Colóquio de Moda, 6., 2010, São Paulo.

Recebido 17/10/2019

Aprovado 11/12/2019 